\title{
Science related information in European television: a study of prime-time news
}

\author{
Bienvenido León
}

According to the few studies carried out on this subject, in spite of its importance and interest for the audience, science has been a marginal topic in television news, and has presented several problems of quality. This article presents the main results of a comparative research on science in European television, focusing on the main prime-time news programs of the leading public and the leading commercial channel, in the five largest countries. A sample of two weeks (2676 stories) was analyzed, with an outcome of 218 science related stories, which were coded (topic, length, explicit news values, contextual information and scientific explanation). Results indicate that the number and airtime of science related stories have increased, compared to a decade ago, but still do not seem to match the interest that citizens declare to have in science. The quality of the information broadcast seems relatively acceptable, although it still needs to be improved in some aspects, for which new formats of news programs would be helpful.

\section{Introduction}

The importance of science information in the mass media has been highlighted by several authors. According to Nelkin (1995: 2), "for most people, the media are their only contact with what is going on in rapidly changing scientific and technical fields, as well as a major source of information about the implications of these changes for their lives."

Several surveys show that citizens are very interested in science and technology and they want science to be covered by the media. For example, a 1998 study made in the United States indicates that 50 percent of Americans were very interested in science discoveries and new technologies, 70 percent in medical discoveries and 52 percent in environmental issues. This level of interest has remained high for more than two decades. Another survey confirms that a majority of the public considers science news to be of equal importance to every other major area of news coverage (Rogers, 1999: 181).

In Europe, surveys also indicate that citizens are interested in science and technology. The latest Eurobarometer on this topic, carried out in 32 countries, corroborates similar results of previous studies, indicating that 88 percent of Europeans are "very interested" or "moderately 
interested" in new medical discoveries; 87 percent in environmental pollution; 78 percent in scientific discoveries, and new inventions and discoveries. Significantly, interest in science related topics is higher that in other topics extensively covered by the media: sport news, 62 percent; politics, 71 percent. However, very few European citizens consider themselves to be "very well informed" on science related topics: environmental pollution, 15 percent; new medical discoveries, 11 percent; new inventions and discoveries, 11 percent; new scientific discoveries, 10 percent. Citizens feel they are much better informed on politics (20 percent) and sports (28 percent) (European Commission, 2005).

Another relevant datum that can be obtained from the same survey is that the main reason for disinterest in science and technology is "lack of understanding." More specifically, 32 percent of respondents who are not at all interested in either "new inventions and technologies" or "scientific discoveries" say that they "do not understand it" (European Commission, 2005).

The role of television as the leading source of information on science and technology is also evident from the results of surveys carried out in several countries (National Science Foundation, 2006). In Europe, according to the previous Eurobarometer on this topic, television is regarded as the most important medium of information on science and technology by 60.3 percent of Europeans, well ahead the other media: press, 37 percent; radio, 27.3 percent (European Commission, 2001).

Therefore, the quantity of science related news in European television is a relevant indicator, as far as it shows if the interest of citizens in science information is matched in the medium that is considered to be the most important one for this purpose.

The quantity of news about science and technology is related to the criteria that media professionals use to select the events they cover, commonly known as "news values." An analysis of the news values in the selection of scientific news can be relevant to explain why some topics are selected while others are left aside. And this can provide some clues to try to increase the presence of science topics in television news. But beyond the amount of information, it is also relevant to analyze the quality of science news, since a large amount of information of a very poor quality would not help citizens to be properly informed on science and technology.

This article presents the results of a comparative study on prime-time news in the five largest European countries. Firstly, it focuses on the amount of information that is broadcast by the leading channels. Secondly, it analyzes the agenda of the topics that are covered and the news values alluded to, in order to explore the criteria of newsworthiness that are followed by the news programs. Thirdly, the study analyzes two relevant variables of the quality of science news, such as the presence of contextual information and scientific explanation, which can help to explain if the scientific topics presented are likely to be properly understood by the audience. Finally, a case study is presented, in order provide a new perspective on how the main analyzed categories can fit together in a particular example.

\section{Literature review}

The importance of and interest for the public contrasts with the scarcity of academic research on science television news. A number of general studies of television news have provided some information on science news. Stemple III (1988) analyzes content in five network newscasts in the US; Roe (2001) in CNN and BBC World; and Harrison (2000) in the main channels of the UK. Although these studies provide some information on science news coverage, in most cases, the sample of news about science is small. 


\section{Quantity}

In most of these works, science and technology appear as marginal topics. For example, Heinderyckx's (1993) research on the content of 17 news programs in six European countries, concludes that the category that includes science and health, represents only 0.75 percent of the stories (on average, 0.1 stories, out of a total of 13.3 stories per broadcast).

A number of studies have focused on television news about specific topics related to science, mainly the environment and medicine. For example, network news coverage of breast cancer (Cho, 2006); agenda building and source selection in health news (Tanner, 2004); coverage of cloning (Holliman, 2004); biological ideas on sexuality (Wilcox, 2003); coverage of research in network news (Kierman, 2003); depictions of physicians in network news (ChoryAssad and Tamborini, 2001); the role of reporter gender in news about sensitive gender-specific cancer (Corbett and Mori, 1999); the potential impact of television news stories about global warming (Nitz and Jarvis, 1998); reporting of the "gay gene" (Miller, 1995); television news viewing and depression (Plotts and Sánchez, 1994); sensationalism in coverage of the Chernobyl accident (Gorney, 1992); coverage of environmental risk by network television (Greenberg et al., 1989); and scientific sources' perception of network news accuracy (Moore and Singletary, 1985). Some of these provide methodological clues and background information which will be useful for our study, as we will see later on. However, from the results of these works it is not possible to obtain a general picture of the quantity and quality of science related news in European television.

Among the few comparative studies on science television news, research on 15 European channels of eight countries, coordinated by the Centre National de la Recherche Scientifique (France) in 1994, found that science was not covered in a massive way, although it varied from one country to another. Germany and France were the countries where more scientific stories were broadcast, whereas Italian channels broadcast the least (Cheveigné, 2006: 89). The results of this study provide a valuable reference for comparison with some of the variables of our study, which was carried out a decade later.

\section{News values and agenda}

News values have been defined as a series of factors "that seem to be particularly important" in the selection of news (Galtung and Ruge, 1965: 64-5). News values work as a "deep structure or a cultural map that journalists use to make sense of the world" (Hall et al., 1978: 54). However, the selection of news is a complex topic, in which, as well as news values, other factors must be taken into account. As Clark and Illman (2006: 497) recall, previous research has indicated that a variety of factors can contribute to the selection process, including interests, experience level of journalists and editors, the need to attract the "right sort" of audience, as well as events and trends within the sphere of science and technology. Another relevant factor is the influence of the production process (Gans, 1980: 158-60).

Researchers have found that there is a great deal of agreement among journalists as far as what they consider to be newsworthy (Boyd, 1988: 108). This points towards the fact that the selection of news that journalists make is driven by the interest that they think the news will draw from the audience. According to Muñoz Torres (1996: 249), news values work as factors that make the reader or viewer reach a "certain degree of implication that makes him/her want to know what is being told."

Several lists of news values have been proposed by journalism manuals and researchers. Muñoz Torres (2002: 100-18) classifies the most relevant contributions into seven categories: spatial factor; time factor; personal appeal; public relevance; the unusual, strange or unexpected; conflict; and formal interest. The most relevant of these categories will be used in our study. 
In the specific case of science reporting, news values seem to be applicable, as in any other field. A study on journalistic practices of science reporters in the British press shows that specialist journalists follow conventional news-value criteria and emphasize the importance of a "relevance to the reader" criterion in the selection of science news (Hansen, 1994).

Although diversity is a central characteristic of European news programs and content varies from one channel to another (Heinderyckx, 1993), several authors support the idea that, in the past few decades, there has been a decline in "serious" topics (e.g. politics), and an increase in the proportion of trivial and sensational stories, related to crime, sports, entertainment and human interest (e.g. Franklin, 1997: 4; Bourdieu, 1997: 60-71; Winston, 2002). Although the importance of this trend has been questioned by other authors (e.g. Brants, 1998: 323; Barnett et al., 2000; McNair, 2000), this environment must be taken into account in order to understand the possible difficulties that science stories can have when competing for airtime with lighter or more sensational topics.

If news values were shared by journalists of the same or different countries, this would lead to a certain level of agreement on the topics selected by different channels of the same country and even of different countries. Therefore we have also studied what topics have been selected, in order to find out if there is a common European agenda of scientific topics.

The importance of the agenda of topics covered by European television news is evident considering the function of mass media known as "agenda-setting," according to which an important effect of the media is the selection of topics to be discussed by society. This analysis of the agenda of scientific topics covered can be relevant, not only to know the level of agreement among the news programs on newsworthiness of the topics, but also because of its possible implications on the influence of the media on each other, as far as the selection of news is concerned, following the so-called "intermedia agenda-setting" (Roberts and McCombs, 1994), which is developed from the "agenda-setting theory" (McCombs and Shaw, 1972).

Previous research on the agenda of science related television news shows that the topics selected vary very much. In Chevigné's (2006: 89) study, 61 percent of the stories were only covered by one channel, and only 7.7 percent of events were covered by more than half of the channels.

\section{Contextual information and scientific explanation}

One of the main criticisms of the media coverage of science and technology is that they do not include the necessary contextual information (e.g. Kua et al., 2004; Rogers, 1999; Rowan, 1999). This makes it more difficult for the audience to understand the meaning of the topic that is presented, since the viewers perceive each story as an isolated element, which they cannot integrate in a system of knowledge (Cantrill, 1993). The public needs to be able to frame the new information in the context of the current scientific knowledge of a specific field, as well as in the significance of the scientific methods and the socioeconomic elements of research practice (Field and Powell, 2001). Otherwise, the information is "interesting but difficult to relate to a current situation or a long-term application" (Kua et al., 2004: 320).

Competition for space (time, in the case of television) among the different topics reduces the chances of including the "background material and qualifications useful in conveying complex technical issues" (Nelkin, 1995: 107). In addition, emphasis on breaking news makes it difficult for the journalist to have enough time to provide contextual information (Gisolf, 1993). In television, the duration of the news stories is presumably related to the possibility of including some background information. Therefore this will be a variable taken into account in our study. 
Some empirical research corroborates that science news often omits contextual information. For example, a study on science news in "prestige newspapers" in the US, which analyzes coverage in the years 1966-70, 1976-80 and 1986-90 concludes that the type of content was relatively similar along the years and "articles frequently omitted methodological and contextual information, features most often mentioned as critical for a complete journalistic account of science" (Pellechia, 1997: 49).

Carol Rogers (1999: 191) also points towards the same idea. Participants in focus groups discussing stories about AIDS drugs wanted some more contextual information about side effects and economic issues: "They wanted to know where this new information fit into the bigger picture of what came before and what was next. Without such context, they had difficulty making sense of the information and deciding just how important it was in the larger scheme of things."

Another important matter on science news is whether it explains, at least in a basic way, the scientific concepts related to the events reported. Research indicates that readers may fail to understand a difficult idea for any of three major reasons. One of them is they "may not grasp the meaning and use of a concept or term" (Rowan, 1990: 26).

Scientific explanations help people to understand the meaning of the scientific topics (Myers et al., 1983; Loman and Mayer, 1983; Mayer, 1983). However, empirical evidence suggests that the media rarely include scientific explanation. Corbett (1995) studied press coverage of wildlife in the US, concluding that, in most cases, scientific concepts are not clearly reflected. Another study on 100 US newspapers reached similar results: the majority of the stories contained little scientific explanation. Ten percent or less of content comprised elucidating (definitions of terms) and/or quasi-scientific explanations (explications of relationships among scientific concepts). Surprisingly, longer stories did not contain significantly more scientific explanation than did shorter stories (Long, 1995).

\section{Research aim and method}

Given the few existing comparative academic works on science related news in European television, this study tries to provide a general view of the situation on the continent, focusing on both quantity and some qualitative aspects. It tries to find out how often science related topics ("science and technology," "health" and "environment") appear on prime-time European news programs. It also analyzes the agenda, the explicit news values and the length of the stories. In addition, it investigates two qualitative aspects of the information: presence of contextual information and scientific explanation.

More specifically, six research questions were formulated:

RQ1: What number of stories about science and technology, health and the environment are broadcast in European prime-time television news programs?

RQ2: How much airtime do these stories receive and what is the average length?

RQ3: Is there a common agenda of scientific topics covered in the different countries and channels?

RQ4: What are the explicit news values?

RQ5: Is contextual information provided?

RQ6: Are scientific explanations included?

Owing to operational reasons, the study is circumscribed to the five largest European markets: France, Germany, Italy, Spain and the United Kingdom. In each country, the main prime-time news programs of the leading public and the leading commercial channel were taped, during 
Table 1. Selected sample of news programmes

\begin{tabular}{lll}
\hline Country & Public channel (program) & Commercial channel (program) \\
\hline UK & BBC1 (Six o'clock News) & ITV (News at Ten) \\
Italy & RAI1 (TeleGiornale 1) & Canale 5 (TeleGiornale 5) \\
France & France 2 (Le journal de & TF1 (Le 20 heures) \\
& 20 Heures) & RTL (RTL Aktuell) \\
Germany & ARD (Tagesschau) & Tele 5 (Informativos Telecinco) \\
Spain & TVE1 (Telediario & \\
& $2^{\text {a edición) }}$ & \\
\hline
\end{tabular}

the third week of September 2003 and 2004. These particular weeks are regarded as representative of the average news week, since no especially relevant event happened during either of the sample weeks.

The leading channels in each country (Table 1) were selected according to the average audience share of the previous year. The decision to include public and commercial channels in the sample is due to the possibility that interest in science can vary from one sector to the other, as a consequence of their different missions. Prime-time for each country was determined according to the criteria of the advertising management company Carat, which are widely accepted internationally.

For the purpose of this research, a story was operationally defined as any segment of the news program with complete sense in itself, included between the opening sequence and the credits of the program. Usually a story includes an introduction made by the anchorperson and the "video-audio package," but sometimes it can consist only of the "video-audio package" (for example, when more than one story is broadcast on different aspects of the same event or topic), a "reader" by the anchorperson or a "reader" covered with images.

The thematic categories used are similar to those of previous television news research (e.g. Harrison, 2000), which usually include three science related categories: "health," "environment" and "science and technology." Following previous studies (e.g. Bauer et al., 1995; Bucchi and Mazzolini, 2003), science stories were operationally defined in a broad sense. It was considered that a story was about "health," "environment" or "science and technology," when it explicitly reported research findings or events related to knowledge, processes or people belonging to these fields.

The selected news programs were recorded and viewed by a delegate researcher in each country, who was typically a Ph.D. or Ph.D. candidate. Each delegate researcher selected the stories related to science included in the sample of 28 programs of his/her country. The total number of analyzed stories was 2676, of which 218 were about "science and technology," "health" and "environment." Afterwards, a randomly selected sample of 400 of the stories (14.9 percent) was coded by a different person, in order to estimate inter-coder reliability. The average percentage of agreement was 84.78 percent (formula of Holsti), which is regarded as acceptable.

The selected stories were then listed, measured in duration and coded by the author and two other coders. The code was pre-tested in a sample of news programs of the UK and Spain. Following the method used by Harcup and O'Neill (2001), the sample of science related stories was viewed, discussed and coded by the author and two other coders together, in order to minimize unreliability.

News values were analyzed following the categories used by Major and Erwin (2004), who studied the explicit news values in the press coverage of environmental risks. We started 
by coding the presence or absence of the same list of news values they used in their study: timeliness, conflict, prominence, significance, and human interest. However, after analyzing the preliminary sample, we realized that prominence did not appear and could be excluded, whereas it was necessary to include other categories, in order to reflect the explicit news values that we found in the sample. Therefore, we added three new categories, following the classification by Muñoz Torres (1996) and finally coded the presence or absence of one or more indicator of the following news values: timeliness, conflict, significance, human interest, proximity, unusualness and visual interest. For the first four news values we followed the criteria of Major and Erwin, whereas for the other three, we followed Muñoz Torres (who compiles definitions from several well known authors). Therefore, the coding was made according to the following operational concepts:

Timeliness appears in references to immediacy (often indicated by the word "today").

Conflict is linked to disputes between individuals, corporations, or other entities.

Significance refers to a large number of people being affected. It is described by other authors as public relevance or impact.

Human interest appears in compelling stories about people's lives or challenges.

Proximity refers to physical or cultural closeness.

Unusualness is linked to certain events that are rare or unexpected.

Visual interest is a characteristic of stories containing compelling images, which can attract the viewer's attention by themselves.

As we have mentioned, this list of news values is derived from several compilations used by well known authors and is adapted to the purpose of our research. Although visual interest is not one of the standard news values, our preliminary test suggested that it was appropriate to include this category, as an adaptation to television of the value "formal interest" which, according to Muñoz Torres (2002: 117), can make a topic of little relevance something the audience may want to know, when covered with the "special bright" of the expression.

Contextual information was operatively defined, in the sense formulated by Nelkin (1995: 83), as any clarification that "provides a link between the findings and their significance, between current knowledge and future application. In order for the reader to be able to evaluate the science and decide just how important it [is] in the larger scheme of things." Following this concept, when any information of this kind appeared, the presence of contextual information was coded.

The presence of scientific explanation is circumscribed to the category of "elucidating explanation" which, as Rowan states (1990: 26) is "designed to help people understand the meaning and use of a term." Elucidating explanations must take into account the distinction between a concept's essential meaning and its associated meaning. For this reason, good elucidating explanations include sets of examples, non-examples and definitions, and "they are more effective at emphasizing a concept's critical feature of meaning than definitions alone" (Rowan, 1999: 211). Following this concept, when any type of elucidating explanation appeared in the sample, regardless of its form (example, non-example or definition), length or level of depth, the presence of scientific explanation was coded as positive.

Finally, the most extensively covered story ("SMART-1 mission to the Moon") was selected as a case study. The purpose of this qualitative research was to analyze how the variables of our research fitted into one particular example. The case showed how the same event was covered by the channels for different reasons (news values) and in very different forms (context and scientific explanation). 


\section{Results and discussion}

\section{Number of stories, airtime and length}

As Table 2 shows, 45 stories about "science and technology" were found during the sample weeks of 2003 and 2004. In relative terms, this is only 1.68 percent of the total number of stories broadcast. "Environment" represents a slightly higher percentage (1.98 percent). News about "health" takes a larger stake, representing 4.48 percent, which is more significant. In general terms, science related topics are far behind other categories such as politics (16.48 percent), sports (13.10 percent) and crime (9.71 percent). Therefore, the three science related categories account for 218 stories (8.14 percent).

Differences among countries are quite significant. France appears as the country that broadcasts the largest proportion of science related stories, whereas Italy is the one with the smallest proportion. Interestingly, in most cases, the countries roughly maintain the same relative position in the three science related thematic categories. For example, France leads the table in "science and technology" and "environment," and is second in "health" (very close to the UK, which is first). Similarly, Italy is in the last position in the three categories. This can be interpreted as a signal of the fact that, in most cases, a country does not show a particular interest in a single category but on science related news, as a whole.

Differences among channels are also very relevant. The French channels broadcast the largest number of science related stories: 59 on TF1; 50 on France 2. On the opposite side, the Italian channel Canale 5, holds the smallest number (1 story), followed by the German channel ARD (10 stories).

It may be expected that public channels broadcast more science related stories than their commercial counterparts do, since their mission statement is frequently associated with more "serious" topics, one of which is science. However, the figures of our study show that the number of science related stories is higher only in the public channels of three countries: the UK (BBC1, 18), Italy (RAI1, 16) and Spain (TVE1, 26). On the contrary, the commercial channels of Germany and France broadcast more stories of the three categories analyzed in this study: RTL, 16 and TF1, 59.

Table 3 shows the total length of the stories about "science and technology," "health" and "environment," as well as the percentage it represents over the total airtime of the news programs. General percentages for all the countries present a similar picture to that of the number of items, with "health" in a significant position (5.49 percent), but "environment" (2.12 percent) and "science and technology" (1.13 percent) as marginal topics.

The comparison among countries leads to similar conclusions as in the classification based on the number of stories, since France is in the first position in "science and technology" and "environment," whereas the UK leads the category of "health." Only in a few cases does the relative position of a country vary. For example, Spain moves from the 4th to the 3rd position in "science and technology" and the UK moves from 3rd to 5th in "environment." However, in general terms, the data on airtime seem to confirm the level of interest of the channels in each thematic category, as reflected in the classification based on the number of stories.

The average length of the news stories (Table 4) is relatively short for "science and technology" (60.73 seconds; well below the general average length of 90.61 seconds), and slightly higher for "environment" (97.26 seconds) and "health" (110.92 seconds). Interestingly, those categories that are more frequently covered and get more airtime, also correspond to those with a longer average duration. This can be regarded as an indicator of the importance that the programs attribute to each topic. 
Table 2. Number of stories by topic (2003-2004)

\begin{tabular}{|c|c|c|c|c|c|c|c|c|c|c|}
\hline & \multicolumn{2}{|c|}{ Science \& technology } & $\%$ & \multicolumn{2}{|c|}{ Environment } & $\%$ & Health & $\%$ & Crime & $\%$ \\
\hline France & \multicolumn{2}{|c|}{15} & 2.05 & \multicolumn{2}{|c|}{32} & 4.36 & 52 & 7.09 & 73 & 9.96 \\
\hline Germany & \multicolumn{2}{|c|}{7} & 1.75 & \multicolumn{2}{|c|}{4} & 1.00 & 15 & 3.75 & 33 & 8.25 \\
\hline Spain & \multicolumn{2}{|c|}{13} & 1.00 & \multicolumn{2}{|c|}{12} & 1.64 & 19 & 2.59 & 62 & 8.45 \\
\hline UK & \multicolumn{2}{|c|}{7} & 1.77 & \multicolumn{2}{|c|}{1} & 1.32 & 24 & 7.66 & 45 & 14.30 \\
\hline Italy & \multicolumn{2}{|c|}{3} & 0.96 & \multicolumn{2}{|c|}{4} & 0.80 & 10 & 2.01 & 47 & 9.46 \\
\hline \multirow[t]{2}{*}{ Total } & \multicolumn{2}{|c|}{45} & 1.68 & \multicolumn{2}{|c|}{53} & 1.98 & 120 & 4.48 & 260 & 9.71 \\
\hline & Sports & $\%$ & \multicolumn{2}{|r|}{ Politics } & \multicolumn{2}{|c|}{$\%$} & \multicolumn{2}{|c|}{ Other topics } & $\%$ & Total \\
\hline France & 59 & 8.05 & \multicolumn{2}{|r|}{89} & \multicolumn{2}{|c|}{12.14} & \multicolumn{2}{|l|}{413} & 56.3 & 733 \\
\hline Germany & 62 & 15.50 & \multicolumn{2}{|r|}{96} & \multicolumn{2}{|c|}{24.00} & \multicolumn{2}{|c|}{183} & 45.7 & 400 \\
\hline Spain & 162 & 22.10 & \multicolumn{2}{|r|}{105} & \multicolumn{2}{|c|}{14.32} & \multicolumn{2}{|l|}{360} & 49.1 & 733 \\
\hline UK & 32 & 10.20 & \multicolumn{2}{|r|}{73} & \multicolumn{2}{|c|}{23.30} & \multicolumn{2}{|l|}{131} & 41.8 & 313 \\
\hline Italy & 35 & 7.04 & \multicolumn{2}{|r|}{78} & \multicolumn{2}{|c|}{15.69} & \multicolumn{2}{|l|}{320} & 64.4 & 497 \\
\hline Total & 350 & 13.10 & \multicolumn{2}{|r|}{441} & \multicolumn{2}{|c|}{16.48} & \multicolumn{2}{|l|}{1407} & 52.6 & 2676 \\
\hline
\end{tabular}

Table 3. Airtime of news by topic in 2003-2004 (seconds)

\begin{tabular}{lccccccc}
\hline & Science and technology & $\%$ & Environment & $\%$ & Health & $\%$ & Total airtime \\
\hline France & 1463 & 2.29 & 3339 & 5.23 & 5566 & 8.72 & 63832 \\
Germany & 355 & 1.24 & 171 & 0.56 & 1396 & 4.89 & 28554 \\
Spain & 1398 & 2.06 & 1041 & 1.53 & 2302 & 3.39 & 67862 \\
UK & 708 & 2.15 & 160 & 0.49 & 3199 & 9.73 & 32870 \\
Italy & 356 & 0.72 & 444 & 0.89 & 848 & 1.72 & 49364 \\
Total & 4280 & 1.77 & 5155 & 2.13 & 13311 & 5.49 & 242482 \\
\hline
\end{tabular}

Table 4. Average length of news stories in 2003-2004 (seconds)

\begin{tabular}{lcccr}
\hline & Science and technology & Health & Environment & All topics \\
\hline France & 97.53 & 107.04 & 104.34 & 87.08 \\
Germany & 50.71 & 93.06 & 42.75 & 71.38 \\
Spain & 107.54 & 121.16 & 86.75 & 92.58 \\
UK & 101.14 & 133.29 & 160 & 105.01 \\
Italy & 118.67 & 84.8 & 111 & 93.32 \\
Average & 60.73 & 110.92 & 97.26 & 90.61 \\
\hline
\end{tabular}

In the general account for all the countries, "health" stories are longer than those about "environment" and, even more clearly, than stories on "science and technology." However, duration varies significantly from one country to another. The UK broadcasts the longest running stories on science related topics, whereas Germany broadcasts the shortest ones, on average. However, these data do not seem to indicate a specially high or low interest for science topics, but a structural characteristic of the news programs since, in the general account for all the topics, UK channels broadcast the longest running stories, whereas German channels broadcast the shortest ones. 
Agenda

There is little coincidence among countries on the agenda of science related topics that are covered. In 2003 only three events were covered by channels of more than one country:

1. "SMART-1. European mission to the Moon," which will be studied in depth later in this article. It was covered by ten stories in four countries (Spain, France, UK and Germany).

2. "Microsoft shuts chat-rooms in its Internet network (MSN)," covered by three stories in two countries (UK and Spain, two).

3. "European day without cars," covered by three stories in two countries (France and Spain, two).

In 2004, four topics were covered in more than one country:

1. "A woman who suffered ovary cancer gives birth to a baby in Belgium, after new treatment." It was covered by four stories in four countries (UK, France, Germany and Spain).

2. "European day without cars." Three stories in two countries (France, two; and Spain).

3. "Dogs are used to detect cancer cells." Two stories in two countries (France and Spain).

4. "Day of Alzheimer's disease." Two stories in two countries (France and Spain).

Therefore, only 3.52 percent of the topics crossed over national borders ( 7 out of a total of 199). This figure shows that there is a very significant distance among countries as far as what stories the news editors suppose will interest their audiences.

As we have seen before, media are said to influence each other on the agenda of topics covered, at least within the same country, where it is easier for the media to follow each other. According to this theory, a higher level of agreement among channels of the same country could be expected, since it is often said that channels tend to broadcast the same topics. However, in the case of science related stories, there is very little coincidence on the topics covered by channels of the same country: France, 8; Spain, 5; UK, 2; Italy, 0; Germany, 0.

Among the ample variety of stories covered, no relevant pattern can be established. However, it is noticeable that a significant number (16 stories) originated in official institutions (e.g. "world day of Alzheimer's disease," "European day without cars," "campaign against obesity" in France, "Day of environment" in Italy, "International day of the heart," "world day of deaf people," etc.).

\section{News values}

Table 5 shows the number of explicit references to news values that appear in the sample. "Significance" is the most frequently alluded value, whereas "proximity" is the least frequent. Values such as "visual interest" and "unusualness" have a surprisingly low number of references, considering the alleged context of sensationalism and loss of seriousness in the news programs.

Some examples of these references follow:

"Significance" is often expressed in the form of the number of people affected by a topic. For example: "4000 people have been warned by the Government that they may have been exposed to an infection" (BBC1, 21 September 2004); "14 million adults" are overweight in France (TF1, 20 September 2004); "80,000 people had eye laser surgery in one year in France" (TF1, 22 September 2004). 
Table 5. Explicit news values

\begin{tabular}{lcr}
\hline & Number of references & $\%$ \\
\hline Proximity & 15 & 4.1 \\
Timeliness & 83 & 23.0 \\
Human interest & 40 & 11.1 \\
Significance & 91 & 25.2 \\
Unusualness & 39 & 10.8 \\
Conflict & 66 & 18.3 \\
Visual interest & 27 & 7.5 \\
Total & 361 & 100 \\
\hline
\end{tabular}

"Timeliness" appears in references such as "today," "this morning" and "tomorrow," which are quite frequent. For example, "Today is the international day of Alzheimer's disease" (TVE1, 21 September 2004).

References to "conflict" include several expressions such as "debate" and "highly controversial" (BBC1, 25 September 2003).

"Human interest" appears in those stories in which a topic is told through a personal story or situation. For example, "Robert suffers from Alzheimer's disease" (France 2, 21 September 2004).

"Unusualness" is expressed in different forms; e.g. the "unusual" event that dogs are used to detect cancer (France 2, 24 September 2004).

An example of reference to "visual interest" is "the first images" of the collision of two galaxies (BBC1, 23 September 2004).

Finally, the most frequent reference to the concept of "proximity" is the mention of the fact that an event is taking place in the same country of broadcast. For example, "Light pollution in France" (France 2, 23 September 2004); "day without cars in Spain" (TVE1, 22 September 2004).

\section{Contextual information and scientific explanation}

Some contextual information appears in 128 stories ( 58.7 percent) of the stories of the three analyzed categories. Contrary to what might be expected, there is no direct relationship between the length of the stories and the presence of contextual information. In most cases, explanations are relatively brief although they provide relevant information, which helps understanding of the meaning of the event presented.

Contextual information appearing in the analyzed stories follows the three main patterns below.

A. Information related to time. It provides some additional data, which can be situated in the past or the future. For example, a story on the "flu vaccination campaign in France" (France 2, 21 September 2004) explains that in the previous year, the flu epidemic affected four million people in the country and cost 400 million euros.

An example of contextual information related to the future is found in one of the stories about the "day of Alzheimer's disease" (TVE1, 21 September 2004). After presenting the current situation of research in this field, the narrator states that in the next five years the most likely developments will be some drugs that can prevent this disease in people with a genetic predisposition. Another example is found in the story about "migration of tree species in France" (TF1, 
22 September 2004), in which a map of the country shows the differences between the current situation and the possible distribution of trees in the year 2100.

B. Information related to space. Some data are provided to explain how the event affects a specific geographic area. For example, in the story on a "campaign to prevent overweight in France," an expert in this field informs us that there is a serious overweight epidemic in the whole of Europe (France 2, 21 September 2004).

C. Information related to causes and consequences. A story about the "interruption of electric energy supply in Italy" (ARD, 28 September 2003) explains the causes of this problem. Consequences are explained in several stories, including "light pollution" in France (France 2, 23 September 2004) and "kidney transplant for children in Spain" (TVE1, 23 September 2004), which states that the main consequence is that after receiving a transplant, children can have a normal life.

Scientific explanation appears in a minority of the stories: 32 , which represent 14.68 percent. In most cases, explanations are brief and simple, as may be expected considering the relatively short length of most stories.

Scientific explanations used are mainly of two types.

A. Explanation of concepts. The meaning of the scientific term used is explained briefly. For example, in a story about "deer on heat in Doñana" (Tele 5, 24 September 2004) the term "bellowing" ("berrea") is explained as "the fight of the male deer to conquer females." Another example is found in the story about a "campaign against overweight in France" (TF1, 20 September 2004). In this case, the term "overweight" is explained, referring it to the scientific measure variable employed (Body Mass Index). In the story about the first images of the "collision of two galaxies" (BBC1, 23 September 2004), the meaning of the phenomenon is explained, comparing it to the "Big Bang," from which the Universe originated.

B. Explanation of processes. Examples of this pattern include the story on the "mother who gives birth to a baby after being treated for ovary cancer in Belgium" (Tele 5, 24 September 2004), in which the narrator explains that the process consists in "re-implanting a part of the ovary which was frozen several years before." The story of the same topic broadcast by France 2 on the same day, also explains, in general terms, the process of in vitro fertilization.

Another example of the same pattern is found in RAI1's story about the announcement by the Italian space agency of "new indicators of possible life in Mars" (20 September 2004). In this case, the narrator says that a high concentration of methane has been found in three areas of the planet and explains the possible process of production of this gas.

Other scientific processes briefly explained in other stories are "how hurricanes are formed and behave" (Tele 5, 25 September 2004) and "ice melting in the poles" (France 2, 23 September 2003).

\section{Qualitative analysis: the case of SMART-1}

Once the results on the selected variables of quantity and quality of the stories have been presented, it is now pertinent to include the results of the case study, in which we can see how these variables work together and how the same topic can be covered in different ways. For this part of the study, we have selected the story that was covered by the largest number of channels in the two sample weeks: "SMART-1 mission to the Moon." ${ }^{1}$ This event was covered by 10 stories during the sample week of 2003, out of a total of 32 on science and technology in this year's sample. It was broadcast in Spain (TVE1 and Tele 5), France (France 2 and TF1), the UK (BBC1), and Germany (ARD). 
The total airtime for this topic was $13 \mathrm{~min} 52 \mathrm{~s}$, which makes an average of 1 min $23 \mathrm{~s}$ per story. The length of each story ranges from $3 \mathrm{~min} 23 \mathrm{~s}$ (BBC1) to $15 \mathrm{~s}$ (TF1). Some of the channels covered the topic for several days, whereas others did it just once: France 2, 3 times; TVE1 and BBC1, 2 times; Tele 5, TF1 and ARD, 1 time. The type of coverage varies from one channel to another, although there is a coincidence in the basic information offered.

This topic accounts for 31.25 percent of the total number of stories on science and technology on that year's sample; a high percentage which is related to the fact that there is a relatively small number of science topics covered. However, it is relevant to notice that a majority of the channels considered this topic to be newsworthy.

The explicit news values that appear in the stories about this topic are timeliness (4 times), unusualness (2 times) and visual interest (1 time). Although there is only one explicit reference to visual interest, the fact that vivid pictures were available to cover this event (the launch itself, celebrations in the control room, etc.), must be regarded as an important reason to select it from among other stories.

In addition, the agreement on the selection of this topic must also be analyzed in the light of television production structures and routines. We must keep in mind that this event originated from a well established official source (European Space Agency), which can often have an easier access to television channels, through expensive public relations operations, which usually include the supply of free images to the channels (video news releases) and paying for some of the expenses of the coverage (e.g. trips).

The way the channels covered this event varied significantly. In some cases, only very basic data were included, whereas in others there was some contextual information and scientific explanation of the meaning of the mission. TF1's coverage of Sunday 28 September 2003 lasts for only 15 seconds, which allows for just the very basic data; namely, that the mission was launched successfully on board of Ariane 5 and this was considered to be "good news for the European space industry." No contextual information or scientific explanation was provided. It adopted the format of a brief piece read by the presenter, mostly illustrated with pictures of the launch of the space rocket.

On the opposite side, BBC1's story broadcast on the same day was 3 minutes and $23 \mathrm{sec}$ onds long. It was reported by a journalist in the studio and included some graphics projected on a chroma-key screen, with an excerpt of an interview with an expert. In this case, some contextual information was included, following the pattern of "information related to time." Firstly, it compared SMART-1 with the US mission that landed on the Moon, 34 years earlier (past). Secondly, it explained what we could learn from the Moon with this mission: how the Moon was formed and evolved (future). Thirdly, it went into some details about the possible existence of some frozen water in the south pole of the Moon, which would mean that it could be colonized sometime (future). Finally, it explained what the mission could mean for future space flights, since it will test a new type of engine, "based on an ion-driven propulsion system" (future).

In this case, no scientific explanation is provided. However, it must be taken into account that, in general, elucidating explanations are not necessary, since the story is explained in terms that are easy to understand by the audience.

The comparison between both ways to cover the same event, can illustrate different approaches to how scientific topics can be presented on television, as well as the intrinsic difficulties the medium has to cover science properly. When some contextual information is included, it is possible to explain the meaning of the event, which can help the viewer to establish the necessary connection between the scientific data and his/her personal experience. When the story is too brief (for example, TF1's coverage), it is extremely difficult to introduce any kind of contextual information, whereas in the longest running stories this can be achieved. 


\section{Conclusion}

The results of this research show that science related news, altogether, has a significant presence in European prime-time news, since it represents 8.15 percent of the number of items and 9.38 percent of airtime. "Science and technology" and "environment," as separate categories are relatively marginal, far behind the main subjects. In contrast, "health" (4.48 percent of stories) is a significant category, which is closer to the main subjects.

This portrays a different situation to that presented by the results of previous studies, in which scientific topics appear to be very scarce in European television news (Cheveigné, 2006; Heinderyckx, 1993). It seems that there has been an increase in these topics within the last decade. For example, although using slightly different thematic categories, as we have mentioned before, Heinderyckx's work revealed that in 1989 less than 0.75 percent of the stories focused on science related topics (science, technology and health).

However, in the current panorama, science related stories are still behind the main subject categories, such as "sports" and "politics." The higher frequency of coverage and the airtime dedicated to topics like "crime" and "sports," defines a highly competitive environment, in which priority is given to sensational and entertaining news, that usually gets higher audience ratings. The fact that, in two countries, the public channels did not broadcast more science stories than their commercial competitors did can be interpreted as a signal of the fact that even public channels have entered, to a certain degree, the fierce battle for audiences.

But the notable presence of "health" news shows that "serious" topics can keep a significant position. "Health" news can easily get the audience's attention, as it provides information that can be immediately connected to daily life and experience. In the case of "environment" and, even more so in "science and technology," the connection is not so immediate.

As we have mentioned before, surveys indicate that European citizens are even more interested in scientific topics than in other subject areas that are more extensively covered by the media. This suggests that the offer of science within European television news does not seem to match the interest that citizens declare to have.

Cheveigné's (2006) study revealed that in 1994 French and German channels covered science more extensively than other countries did, whereas Italian channels had the lowest frequency in the coverage of this topic. A decade later, the results of our study show that French channels still keep the highest interest in science (13.50 percent of the stories), while German channels have reduced the percentage ( 6.50 percent). Italian channels remain in the last position in the number of science related stories broadcast (3.42 percent).

As we have mentioned before, the average length of the stories can be regarded as an indicator of the relevance that channels concede to each category. From this we can infer that "health" stories are very relevant for the channels, with an average length of 110.92 seconds, higher than the general average for all the topics ( 90.61 seconds). On the opposite side, "science and technology" stories are below the average general duration, with only 60.73 seconds. "Environment" is slightly above the average general duration (97.26 seconds).

Cheveigné's study indicates that in 1994 the length of the stories varied between 1 and 2 minutes. French channels TF1 and France 2 were among the channels broadcasting longer items. The present study shows that there has been an evolution towards longer stories, which in some cases can be even longer than 3 minutes. According to our results, nowadays UK channels broadcast the longest stories.

Although there is no direct relationship between the presence of contextual information and the length of the stories, this evolution toward longer stories must be regarded as potentially positive for the quality of science news. As we have seen in the case study of SMART-1, 
when the stories are very short, they do not have a chance to include contextual information and, therefore, it may be more difficult for the audience to understand them properly.

The diversity of the topics covered by the channels shows that there is no common European agenda of scientific news. As we have shown, only seven topics (3.52 percent) were covered in more than one country. Even within the same country there is little coincidence in the agenda of topics covered, which confirms the results of Cheveigné's (2006) research. The fact that such a small number of topics are considered to be newsworthy by more than one channel proves that journalists maintain different criteria for the selection of news, contrary to what some authors suggest (Boyd, 1988: 108).

The study of the explicit news values shows that the criteria followed are likely to contribute to the selection of relevant news for the audience. There is a high percentage of references to significance (25.2 percent), compared to unusualness (10.8 percent) and visual interest (7.5 percent), which may lead to selection of some topics that make "good television," regardless of the relevance they may have for the audience. It is also interesting to note that there are very few references to proximity, which shows that journalists do not see the need to link scientific topics to a close area of experience of the audience.

The above mentioned news values provide some valuable clues to try to increase the presence of science in the news. However, this part of the research has the limitation that it has only studied explicit news values. Further research would be needed in order to investigate implicit news values, which would allow us to draw a more complete picture of the criteria followed by the journalist to decide what is news. It would also be necessary to research professional routines, which, as we have seen in the case of SMART-1, can have a relevant influence in the selection of a particular topic.

Contrary to what some authors state (Pellechia, 1997; Rogers, 1999), the results of the present study show that contextual information appears in a significant number of stories (58.7 percent). In principle, this must be regarded as another positive indicator of the quality of the scientific news. However, it must be noticed that in this case we have coded as positive the existence of any kind of contextual information. Further research would be necessary to analyze the pertinence and quality of the information provided.

The presence of contextual information and scientific explanation is also related to the background knowledge of the journalists. When science news is covered by specialized journalists it is more likely that they are in the position to provide this type of explanatory information. This may help to understand why in the analyzed case study (SMART-1), the BBC's coverage provides more contextual information than that of the other channels, since in the UK channel, the information is provided by a "science correspondent." However, further research would also be necessary to corroborate the relationship between the specialization of journalists and the inclusion of contextual information and scientific explanation.

On the contrary, the fact that very few stories include some kind of scientific explanation (14.68 percent) must be regarded as a negative indicator of the quality of the news. As we have mentioned, when concepts are not explained, even in a basic way, it is more difficult for the audience to make sense of the information presented. As we have seen in the case of SMART-1, even some news stories that are longer than the average do not include any scientific explanation.

Generally speaking, the results of our study seem to draw a relatively acceptable picture of the quantity and quality of science related news in European prime-time television. On the one hand, the number of science related topics seems to have increased in the last decade, although it still does not seem to be enough to match the interest that citizens declare to have 
in science and technology. On the other hand, although there is room for improvement, the explicit news values alluded to and the significant presence of contextual information seem to indicate that journalists take into account some criteria that should help to supply science information of good quality to the audience.

In contrast, the fact that scientific concepts are explained only in a minority of the stories must be interpreted as a weakness of the coverage. Although television often focuses on the results or applications of science, rather than on scientific concepts, the inclusion of some explanation can help the viewer to understand and follow science in this medium.

This characteristic can be related to the fact that, in general, television news programs are structured according to formats that impose rigid conditions, as far as duration and form are concerned. Some topics, like science, do not seem to fit well into these formats and find it difficult to make their way to air, and even more difficult to be presented in an efficient way.

Alternative formats for news programs are needed, which allow for stories of a longer duration, as a basic condition to include contextual information and explanations of scientific concepts. In addition, new ways of presenting information seem to be necessary, so that science can be presented in a more accessible way. The format used by BBC1 to explain the meaning of the SMART-1 mission seems appropriate. New formats could be the initial steps towards the improvement of the quality of science news. This seems to be one of the main obstacles science needs to overcome, in order to increase its presence in television to reach the position that audiences demand. However, further research on audience reception of scientific news would be necessary to corroborate this.

\section{Acknowledgements}

This study has been sponsored by the Spanish Ministry of Education and Science (BSO200202961). A preliminary version of this paper was presented at the PCST-9 Conference in Seoul (June 2006). The author is grateful to the participants, for their helpful suggestions. The author gratefully acknowledges the help of the delegate researchers Dr. Karen Sanders (UK), Dr. Jorge Milán (Italy), Charlene Fabry (France), Kathleen Bierman (Germany) and María Tobalina (Spain); as well as Natalia Rodríguez and María Tobalina, who helped in the coding process. Special thanks are due to the anonymous reviewers of Public Understanding of Science for their invaluable suggestions.

\section{Note}

1 SMART-1, Europe's first mission to the Moon, was launched successfully from the Guiana Space Center, on board the Ariane 5 rocket, on 27 September 2003. It was scheduled to arrive on the Moon in March 2005. This was the first in a new series of "Small Missions for Advanced Research in Technology" (SMART-1), which is mainly designed to demonstrate innovative and key technologies for future deep space science missions. The first technology to be demonstrated was the "Solar Electric Primary Propulsion," a highly efficient and lightweight system, ideal for space missions beyond our solar system.

\section{References}

Barnett, S., Seymour, E. and Gaber, I. (2000) "From Callaghan to Kosovo: Changing Trends in British Television News," University of Westminster. URL (consulted 20 September 2003): http://www.itc.org.uk/ itc_publications/audience_research/index.asp

Bauer, M., Durant, J., Ragnarsdottir, A. and Rudolphsdottir, A. (1995) Science and Technology in the British Press, Research Report, 1946-1990. London: Science Museum.

Bourdieu, P. (1997) Sobre la televisión. Barcelona: Anagrama. 
Boyd, A. (1988) Broadcast Journalism: Techniques of Radio \& TV News. Oxford: Focal Press.

Brants, K. (1998) "Who's Afraid of Infotainment?," European Journal of Communication 13(3): 315-35.

Bucchi, M. and Mazzolini, R. (2003) "Big Science, Little News: Science Coverage in the Italian Daily Press, 1946-1997," Public Understanding of Science 12: 7-24.

Cantrill, J. (1993) "Communication and our Environment: Categorizing Research in Environmental Advocacy," Journal of Applied Communication Research 21: 36-66.

Cheveigné, S. (2006) "Science and Technology on TV News: The Creation of Content," in J. Willems and W. Göpfert (eds) Science and the Power of TV, pp. 85-100. Amsterdam: VU University Press \& Da Vinci Institute.

Cho, S. (2006) "Network News Coverage of Breast Cancer, 1974 to 2003," Journalism and Mass Communication Quarterly 83(1): 116-30.

Chory-Assad, R. and Tamborini, R. (2001) "Television Doctors: An Analysis of Physicians in Fictional and NonFictional Television Programs," Journal of Broadcasting and Electronic Media 45(3): 499-521.

Clark, F. and Illman, D. (2006) "A Longitudinal Study of the New York Times Science Times Section," Science Communication 27(4): 496-513.

Corbett, J. (1995) "When Wildlife Make the News: An Analysis of Rural and Urban North-Central US Newspapers," Public Understanding of Science 4: 397-410.

Corbett, J. and Mori, M. (1999) "Gender-Specific Reporters? Twenty-four Years of Network TV Coverage," Science Communication 20(4): 395-408.

European Commission (2001) Eurobarometer 55.2. URL (consulted June 2005): http://europa.eu.int/comm/ public_opinion/archives/eb/ebs_154_en.pdf

European Commission (2005) Special Eurobarometer: Social Values, Science and Technology. URL (consulted March 2006): http://www.eu.nl/public_opinion/archives/ebs/ebs_225_report_en.pdf

Field, H. and Powell, P. (2001) "Public Understanding of Science versus Public Understanding of Research" (Policy Perspective), Public Understanding of Science 10: 421-6.

Franklin, B. (1997) Newszak and News Media. London: Arnold.

Galtung, J. and Ruge, M. (1965) "The Structure of Foreign News: the Presentation of the Congo, Cuba and Cyprus Crises in Four Norwegian Newspapers," Journal of International Peace Research 1: 64-91.

Gans, H.J. (1980) Deciding What's News. London: Constable.

Gisolf, A. (1993) "Science on Television," in K. Ackrill (ed.) The Role of the Media in Science Communication, pp. 113-17. London: Ciba Foundation.

Gorney, C. (1992) "Numbers versus Pictures: Did Network Television Sensationalize Chernobyl Coverage?," Journalism Quarterly 69(2): 455-65.

Greenberg, M.R., Sandsman, P.M., Sachsman, D.B. and Salomone, K.L. (1989) "Network Television News Coverage of Environmental Risks," Environment 31(2): 16-20, 40-3.

Hall, S., Critcher, Ch., Jefferson, T., Clarke, J. and Roberts, B. (1978) Policing the Crisis: Mugging, the State, and Law and Order. London: Macmillan.

Hansen, A. (1994) "Journalistic Practices and Science Reporting in the British Press," Public Understanding of Science 3: 111-14.

Harcup, T. and O'Neill, D. (2001) “What Is News? Galtung and Ruge Revisited,” Journalism Studies 2(2): 261-80.

Harrison, J. (2000) Terrestrial TV News in Britain: The Culture of Production. Manchester: Manchester University Press.

Heinderyckx, F. (1993) “Television News Programmes in Western Europe: A Comparative Study,” European Journal of Communication 8(4): 425-50.

Holliman, R. (2004) "Media Coverage of Cloning: A Study of Media Content, Production and Reception," Public Understanding of Science 13(2): 107-30.

Kierman, V. (2003) "Diffusion of News about Research," Science Communication 25: 3-13.

Kua, E., Reder, M. and Grossel, M.J. (2004) "Science in the News: A Study of Reporting Genomics," Public Understanding of Science 13: 309-22.

Loman, N.L. and Mayer, R.E. (1983) "Signaling Techniques that Increase the Understanding of Expository Prose," Journal of Educational Psychology 75: 402-12.

Long, M. (1995) "Scientific Explanation in US Newspaper Science Stories," Public Understanding of Science 4: 119-30.

McCombs, M.E. and Shaw, D.L. (1972) “The Agenda-Setting Function of Mass Media,” Public Opinion Quarterly 36: $176-87$.

McNair, B. (2000) Journalism and Democracy: An Evaluation of the Political Sphere. London: Routledge.

Major, A. and Erwin, L. (2004) "Environmental Risks in the News: Issues, Sources, Problems and Values," Public Understanding of Science 13: 295-308. 
Mayer, R.E. (1983) "What We Have Learned about Increasing the Meaningfulness of Scientific Prose," Science Education 67(2): 223-37.

Miller, D. (1995) "Introducing the 'Gay Gene': Media and Scientific Representation," Public Understanding of Science 4: 269-84.

Moore, B. and Singletary, M. (1985) "Scientific Sources' Perceptions of Network News Accuracy," Journalism Quarterly 62: 816-23.

Muñoz Torres, J.R. (1996) El interés informativo. Madrid: Fragua.

Muñoz Torres, J.R. (2002) Por qué interesan las noticias. Un estudio de los fundamentos del interés informativo. Barcelona: Herder.

Myers, J.L., Hansen, R.S., Robson, R.C. and McCann, J. (1983) “The Role of Explanation in Learning Elementary Probability," Journal of Educational Psychology 75: 374-81.

National Science Foundation (2006) Science and Engineering Indicators 2006. Arlington, VA: NSF. URL (consulted August 2006): http://www.nsf.gov/statistics/seind06/c7/c7h.htm

Nelkin, D. (1995) Selling Science: How the Press Covers Science and Technology. New York: Freeman and Company.

Nitz, M. and Jarvis, S. (1998) "Science in the News: The Potential Impact of Televised News Stories about Global Warming," paper presented at the 5th International Conference on Public Communication of Science and Technology, Berlin, September. URL (consulted May 2005): http://www.fu-berlin.de/pcst98/seiteauth.htm

Pellechia, M. (1997) "Trends in Science Coverage: a Content Analysis of Three US Newspapers," Public Understanding of Science 6: 49-68.

Plotts, R. and Sanchez, D. (1994) "Television Viewing and Depression: No News is Good News," Journal of Broadcasting and Electronic Media 38: 79-90.

Roberts, M. and McCombs, M. (1994) "Agenda Setting and Political Advertising: Origins of the News Agenda," Political Communication 11(3): 249-62.

Roe, K. (2001) "One Planet-One News? A Comparison of News Coverage by CNN and BBC World TV," in K. Renckstorf, D. McQuail and N. Jankowski (eds) Television News Research: Recent European Approaches and Findings, pp. 269-77. Communications Monographs, Vol. 2. Berlin: Quintessence Books.

Rogers, C. (1999) “The Importance of Understanding Audiences," in S.M. Friedman, S. Dunwoody and C.L. Rogers (eds) Communicating Uncertainty: Media Coverage of New and Controversial Science, pp. 179-200. Mahwah, NJ: Lawrence Erlbaum.

Rowan, K. (1990) "Strategies for Explaining Complex Science News," Journalism Educator 45(2): $25-31$.

Rowan, K. (1999) "Effective Explanation of Uncertain and Complex Science," in S.M. Friedman, S. Dunwoody, and C.L. Rogers (eds) Communicating Uncertainty: Media Coverage of New and Controversial Science, pp. 201-23. Mahwah, NJ: Lawrence Erlbaum.

Stemple III, G. (1988) “Gatekeeping: The Mix of Topics and the Selection of Stories," Journalism Quarterly 62(4): 791-6.

Tanner, A.H. (2004) "Agenda Building, Source Selection, and Health News at Local Television Station: A Nationwide Survey of Local Television Health Reporters," Science Communication 25(4): 350-63.

Wilcox, S. (2003) "Cultural Context and the Conventions of Science Journalism: Drama and Contradiction in Media Coverage of Biological Ideas about Sexuality," Science Communication 20(3): 225-47.

Winston, B. (2002) “Towards Tabloidization? Glasgow Revisited, 1975-2001,” Journalism Studies 3(1): 5-20.

\section{Author}

Bienvenido León, Ph.D., a former journalist and documentary filmmaker, is an Associate Professor of Science Communication in Television and Television Production at the University of Navarra, Pamplona, Spain. He has published several books and articles on science communication, including Science on Television. The Narrative of Science Documentary (Luton: Pantaneto Press, 2007). Correspondence: Departamento de Proyectos Periodísticos, Edificio Biblioteca, Universidad de Navarra, 31080 Pamplona, Spain; e-mail: bleon@unav.es 